Rev. Bras. Saúde Prod. Anim., Salvador, v.13, n.1, p.83-96 jan/mar, 2012 http://www.rbspa.ufba.br ISSN 15199940

\title{
Simulação dos efeitos de fatores dietéticos sobre a população de protozoários ruminais
}

\author{
Simulation of the effects of dietary factors on the profile of rumen protozoa population
}

\author{
JESUS, Lisiane Pereira de $^{1^{*}}$;CABRAL, Luciano da Silva ${ }^{1}$; ESPINOSA, Mariano \\ Martinez ${ }^{1}$; ABREU, Joadil Gonçalves de ${ }^{1}$; ZERVOUDAKIS, Joanis Tilemahos ${ }^{1}$; \\ MORENZ, Mirton José Frota ${ }^{2}$
}

\author{
${ }^{1}$ Universidade Federal de Mato Grosso, Faculdade de Medicina Veterinária, Departamento de Zooetcnia, \\ Cuiabá, Mato Grosso, Brasil. \\ ${ }^{2}$ Universidade Federal Rural do Rio de Janeiro, Seropédica, Rio de Janeiro, Brasil. \\ *Endereço para correspondência: lisiane.jesus@ig.com.br
}

\section{RESUMO}

Objetivou-se desenvolver modelos estatísticos que possam estimar as variações da população de protozoários ruminais mediante alterações na dieta, por meio de utilização dos parâmetros: teores de fibra em detergente neutro e proteína bruta, consumo de matéria seca e $\mathrm{pH}$, bem como verificar se as variáveis peso vivo e raça exercem influência sobre a população de protozoários do rúmen. Foram construídas planilhas por meio do software Excel e registrados dados referentes aos parâmetros acima mencionados e sobre o perfil da microbiota ruminal. Estas variáveis foram utilizadas e testadas para obtenção das equações para predição do perfil da microbiota. Os modelos estatísticos obtidos foram verificados por análise residual e para a seleção das variáveis foi considerado o nível de significância de $5 \%$, mediante a utlização do software MINITAB Versão 15 (2010). As equações de regressão obtidas a partir dos dados analisados permitem inferir que: ocorreu um aumento no número de protozoários totais proporcional à elevação do $\mathrm{pH}$; as variáveis raça, peso e aditivos exerceram efeito significativo sobre a população de protozoários totais; à medida que elevou-se o consumo de matéria seca, diminuiu o número de protozoários ruminais; o aumento do teor de fibra em detergente neutro na dieta promoveu incremento no número de protozoários; quanto maior o teor de proteína bruta, menor o número de protozoários totais. Os modelos obtidos permitem estimar o número de protozoários em função das variáveis raça, peso, $\mathrm{pH}$, consumo de matéria seca, teores fibra em detergente neutro e proteína bruta da dieta e presença ou ausência de aditivos.

Palavras-chave: ciliados ruminais, meta-análise, microbiota ruminal

\section{SUMMARY}

The objective was to develop statistical models that can estimate the variations of the rumen protozoa population through changes in diet, using as parameters: neutral detergent fiber and crude protein, dry matter intake and $\mathrm{pH}$, and to verify whether the variables weight and race influence on the population of protozoa in the rumen. Were built using Excel spreadsheets and recorded data on the aforementioned parameters and the profile of the rumen microbiota. These variables were used and tested to obtain the equations for predicting the profile of the microbiota. The models obtained were checked by residual analysis and selection of variables was performed considering the significance level of $5 \%$, using the software MINITAB Release 15 (2010). The regression equations obtained from the analyzed data may imply that: there was an increase in the number of total protozoa proportional to the elevation of $\mathrm{pH}$, the variables race, weight and additives exerted a significant effect on the protozoa population totals, as increased if dry matter intake decreased the number Protozoa; increasing the neutral detergent fiber content in the diet promoted an increase in the number of protozoa, the higher the crude protein, the lower the total number of protozoa. The models allow to estimate the number of parasites in the light of these variables: $\mathrm{pH}$, dry matter intake, neutral detergent fiber and crude protein contents of diet and the presence or absence of additives.

Keywords: meta-analysis, rumen ciliates, rumen microbial 


\section{INTRODUÇ̃̃̃O}

Os componentes químicos, fisiológicos e nutricionais da dieta influenciam o crescimento de micro-organismos ruminais, mas os principais modificadores da fermentação ruminal segundo Hoover \& Stokes (1991) foram $\mathrm{pH}$ ruminal e a taxa de passagem, no entanto, ambos são afetados pela dieta.

Nagajara et al. (1992) e Nogueira Filho et al. (2000) atribuíram a redução ou eliminação da população de microorganismos ruminais de bovinos à queda do $\mathrm{pH}$ ruminal e a rápida taxa de passagem, quando os níveis de concentrado na ração são aumentados.

Araújo et al. (2007) concluíram que a ingestão reduzida de alimentos ocasiona menor taxa de passagem do material sólido do rúmen para o intestino, desta forma, as partículas fibrosas permanecem maior tempo no ambiente ruminal, o que favorece o estabelecimento e crescimento dos protozoários.

Benez (2007) afirmou que os níveis de fibra em detergente neutro (FDN) podem exercer grande influência no consumo de matéria seca ao associar este fator à menor taxa de passagem da FDN, em relação a outros nutrientes da dieta, e como consequência, maior é o tempo de permanência da digesta nos pré-estômagos.

Matos et al. (2008), ao avaliarem a população de protozoários ciliados do rúmen de ovinos observaram que a porcentagem de protozoários nos animais em estudo só variou $(p<0,05)$ para o gênero Eodinium, e justificaram esta variação pelo elevado teor de proteína bruta $(\mathrm{PB}=17,82 \%)$ na dieta ofertada.

Além do consumo de matéria seca e dos teores de FDN e PB na dieta, fatores metabólicos individuais dos hospedeiros podem exercer influência na ocorrência e na concentração dos ciliados do rúmen (KITTELMANN \& JANSSEN, 2002).

A despeito de todos esses trabalhos realizados, os efeitos desta população nos processos digestivos de ruminantes ainda são discutidos, o que evidencia a necessidade de se aprofundar os estudos neste sentido. O emprego de modelos estatísticos como ferramenta para predição de variações no perfil da microbiota ruminal pode servir de escopo, para elucidar os diferentes tipos de interações estabelecidas entre os componentes de um sistema biológico tão complexo como o rúmen. Neste sentido, objetivou-se desenvolver modelos estatísticos que possam estimar as variações da população de protozoários ruminais, mediante presença de outros fatores que interferem no perfil da microbiota como: peso vivo, raça, teores de fibra em detergente neutro (FDN) e proteína bruta $(\mathrm{PB})$, consumo de matéria seca (CMS) e pH.

\section{MATERIAL E MÉTODOS}

Ao se considerar que a natureza diversa dos diferentes estudos, tanto em termos de delineamento como em relação aos métodos empregados na realização de cada um deles é a principal dificuldade para combinar os resultados em uma meta-análise, efetuou-se, para obtenção das equações, uma extensa busca na literatura nacional. Destas forma, foram excluídos os artigos provenientes de pesquisas internacionais para manter a homogeneidade dos dados e evitar o surgimento de "outliers". Os periódicos consultados foram: Acta Scientiarum (dezembro de 2000), Arquivo Brasileiro de Medicina Veterinária e Zootecnia (abril de 2001 a agosto 2009), Boletim de Indústria Animal (junho de 2004), Ciência e Agrotecnologia (janeiro e 
fevereiro de 2007), Revista Brasileira de Saúde e Produção Animal (janeiro a março de 2008), Revista Brasileira de Zootecnia (janeiro de 2000 a março de 2008) e Revista Pesquisa Agropecuária Brasileira (junho de 1998 e julho de 2008). A revisão de literatura incluiu artigos publicados entre o período de junho de 1998 até agosto de 2009.

A partir da revisão desses artigos, uma tese e duas dissertações, planilhas foram montadas mediante utilização do software Excel para registro dos dados referentes a: peso, raça, $\mathrm{pH}, \mathrm{CMS}$ e teores de FDN e PB da dieta como dados de entrada e o perfil da microbiota ruminal, como dados de saída, este último item representado pelo número de protozoários totais $\times 10^{4}$ células $/ \mathrm{mL}$. Estas variáveis foram utilizadas para obtenção das equações para predição do perfil da microbiota.

$\mathrm{Na}$ elaboração da equação para predição do perfil da microbiota que utilizaram como variáveis independentes $\mathrm{o} \mathrm{pH}$ e aditivos foram consultados: Nogueira Filho et al. (1998), Burger et al. (2000), Franzolin \& Franzolin (2000), Nogueira Filho et al. (2000), Sálvio e D'Agosto (2001), Franzolin et al. (2002), Manella \& Lourenço (2004), Ortolan. (2005), Valinote et al. (2005), Domingues (2006), Rivera (2006), Vidal et al. (2007), Martinele et al. (2008a), Martinele et al. (2008b), Soares et al. (2008); Saran Netto et al. (2009). A tese e duas dissertações utilizadas na metaanálise constam nas referências, pois são essenciais para garantir a reprodutibilidade do trabalho.

Todos os dados provenientes dos estudos foram tabulados em tabela do aplicativo Microsoft Excel, efetuada a transformação dos resultados de cada estudo numa métrica comum, e, posteriormente, feita a verificação da homogeneidade dos resultados. Estudos que apresentavam alguma das variáveis avaliadas sem valor atribuído foram excluídos devido a impossibilidade de se realizar análise por meio do software MINITAB (versão 15). A exclusão de dados também foi determinada pelo surgimento de "outliers", ou seja, valores discrepantes provenientes de observações que apresentam um grande afastamento das demais da série ou que são inconsistentes. A existência de "outliers" implica, tipicamente, em prejuízos à interpretação dos resultados dos testes estatísticos aplicados às amostras, uma vez eliminados, todas as etapas para obtenção dos modelos eram refeitas.

A verificação da adequação dos modelos foi realizada ao considerar a análise residual, o valor do coeficiente de determinação $\left(\mathrm{R}^{2}\right)$ e o $p$-valor dos modelos $(\mathrm{p}<0,05)$. Após verificada a adequação dos modelos, a significância das variáveis foi estabelecida mediante utilização da razão $t$ e seu respectivo valor de $p$, considerado um nível de significância de $5 \%$. Os dados foram analisados por meio do software MINITAB (2010).

\section{RESULTADOS E DISCUSSÃO}

Para o número de protozoários totais

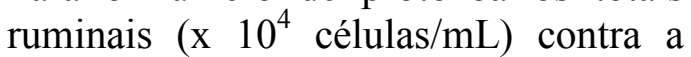
variável independente $\mathrm{pH}$, foi obtida a seguinte equação de regressão ajustada:

$$
\operatorname{Raiz}(\hat{\mathrm{Y}})=-17,458+3,3415 \mathrm{pH}-2,2133 \text { aditivos }+0,0011 \text { vol*con }
$$

Em que: vol*con refere-se à interação entre as variáveis volumoso e concentrado.
A variável independente aditivo mostrou exercer efeito significativo sobre $\mathrm{o}$ número de protozoários, desta forma foi 
Rev. Bras. Saúde Prod. Anim., Salvador, v.13, n.1, p.83-96 jan/mar, 2012 http://www.rbspa.ufba.br ISSN 15199940

considerada no modelo para obtenção de um melhor ajuste. Reconhecidamente, os aditivos reduzem a população de protozoários ruminais, fato constatado por Mackie et al. (2002), Martinele et al. (2008b), Rispoli et al. (2009), Gomes et al. (2010).

A variável interação volumoso:concentrado deve ser considerada na obtenção do modelo e assim alcançar um melhor ajuste. Dias et al. (2000) constataram efeito dos níveis de concentrado sobre $\mathrm{o} \mathrm{pH}$ do líquido ruminal (Tabela 1), que decresceu linearmente quando estes níveis variaram de 25 a $75 \%$ de concentrado. Do mesmo modo, Cecava et al. (1991) verificaram redução do $\mathrm{pH}$ ruminal de 6,10 para 5,86 , quando forneceram níveis alto e baixo de fibra para novilhos, e este comportamento foi um reflexo da substituição progressiva da FDN por carboidratos solúveis, cuja taxa de fermentação é mais rápida.

Tabela 1. Variáveis, coeficientes, erro padrão dos coeficientes, razão $t$ e valores de $p$ para o modelo de regressão estimado para protozoários totais versus $\mathrm{pH}$, aditivos e interação volumoso e concentrado

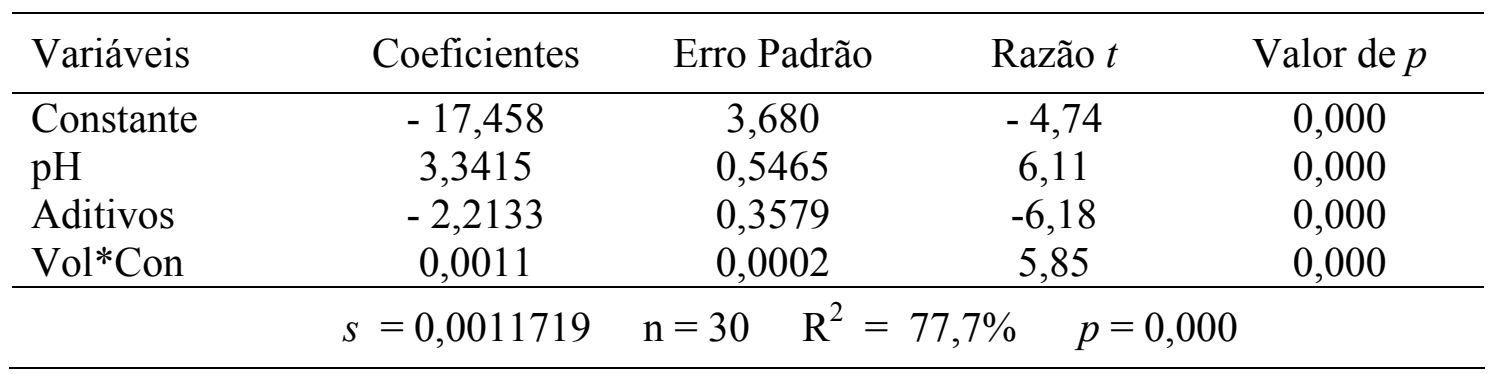

$\overline{\mathrm{Vol}}{ }^{*} \mathrm{Con}=$ interação entre as variáveis volumoso e concentrado.

Gonçalves et al. (2001) observaram decréscimo do $\mathrm{pH}$ ruminal mediante aumento dos níveis de concentrado na dieta. Van Soest (1994) atribui esse comportamento à menor atividade de ruminação observada quando níveis crescentes de concentrado são adicionados, o que induz à redução da secreção salivar, importante na manutenção da atividade tamponante e responsável pelo controle do $\mathrm{pH}$ ruminal.

$\mathrm{O} \mathrm{pH}$ exerce efeito significativo sobre o número de protozoários totais $(\mathrm{p}<0,05)$. A medida que o $\mathrm{pH}$ aumenta, ocorre um incremento no número de protozoários totais, estes dados estão em concordância com as observações de vários autores, que afirmaram existir diminuição ou até mesmo eliminação dos protozoários em acidez elevada (NOGUEIRA FILHO et al., 2000). Franzolin \& Dehority (2010) afirmaram que longos períodos de baixo $\mathrm{pH}$ ruminal, provavelmente, são mais prejudiciais para a sobrevivência dos protozoários ciliados no rúmen que outros fatores.

Alterações no $\mathrm{pH}$ ruminal podem ocorrer também devido à natureza da dieta e a características inerentes aos animais, como taxa de ingestão alimentar, salivação, taxa de fermentação e concentração de seus produtos finais (RUSSEL \& RYCHLIK, 2001; COALHO et al., 2003).

$\mathrm{O}$ pH ruminal é função da relação entre a taxa de produção de ácidos graxos voláteis pela microbiota ruminal $\mathrm{e}$ os mecanismos tamponantes (secreção salivar, absorção e passagem). Com base na equação e na Figura 1, pode-se perceber que a diminuição do $\mathrm{pH}$ 
ruminal abaixo de 6,0 promoveu uma queda acentuada na concentração de protozoários totais, o que indica que se for interesse manter essa população ativa e numerosa no rúmen, estratégias devem ser utilizadas para manutenção do $\mathrm{pH}$ ruminal acima de 6,0 (Figura 1).

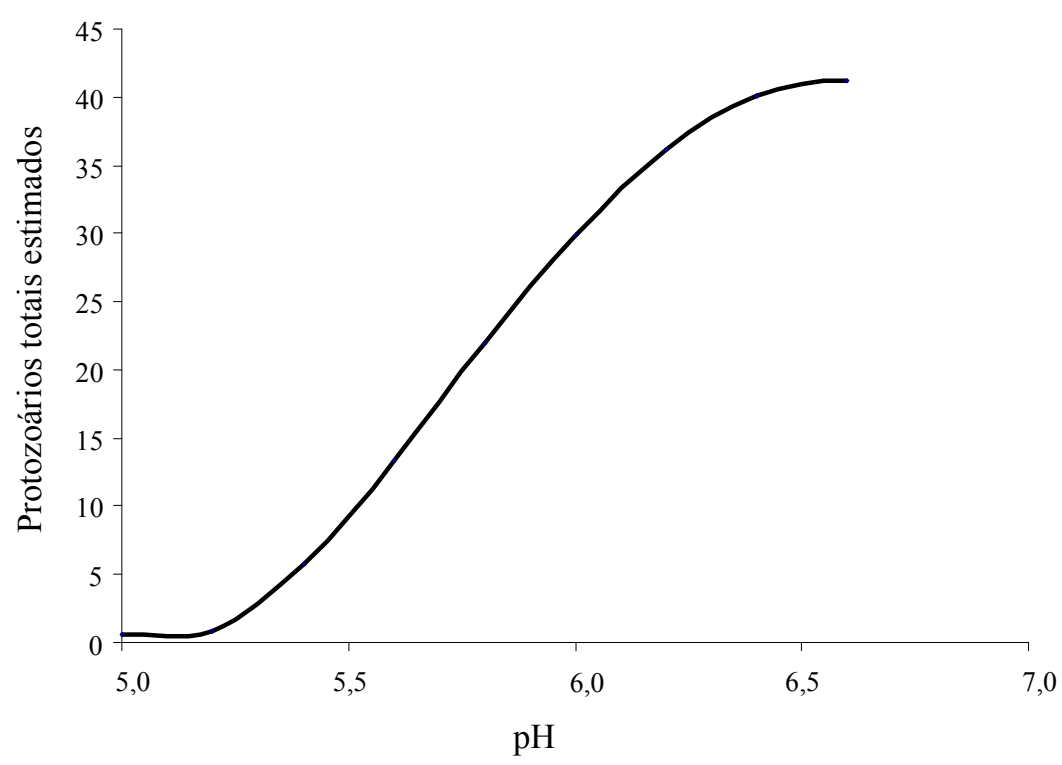

Figura 1. Estimativa do número de protozoários totais no rúmen $\left(\mathrm{x} 10^{4}\right.$ células $\left./ \mathrm{mL}\right)$ em função da variação do $\mathrm{pH}$ ruminal (sem aditivos)

A redução do $\mathrm{pH}$ do meio de crescimento poder afetar a permeabilidade da membrana celular, a estabilidade de macromoléculas e a atividade de enzimas intra e extracelulares. Portanto, mesmo que ocorra variação do $\mathrm{pH}$ extracelular, os micro-organismos tendem a manter o $\mathrm{pH}$ intracelular constante, ou seja, próximo à faixa ótima para seu crescimento. Os mecanismos utilizados por esses micro-organismos para a manutenção do $\mathrm{pH}$ intracelular são consumidores de energia e, desta forma, podem causar redução do seu crescimento (MADIGAN \& MARTINKO, 2006). Para o número de protozoários totais ruminais ( $\mathrm{x} \quad 10^{4}$ células $/ \mathrm{mL}$ ) contra as variáveis independentes raça e CMS, foi obtida a seguinte equação de regressão ajustada:

$$
(\hat{Y})^{2}=20111-6205 \text { raça }_{1}-3184,3 \text { raiz CMS }(k g)
$$

A variável independente raça ${ }_{1}$, referindose a animais da raça Holandesa e Girolanda, exerceu efeito significativo sobre a população de protozoários totais, da mesma forma como fatores inerentes ao hospedeiro e a espécie animal também tem interferido no perfil da microbiota (NOGUEIRA FILHO et al., 1998;
NOGUEIRA FILHO et al., 2004; FORTALEZA et al., 2009; RÍSPOLI et al., 2009).

O CMS exerceu efeito significativo sobre o número de protozoários totais, ou seja, à medida que aumenta o CMS, diminui a população de protozoários ruminais (Tabela 2). Dijkstra \& Tamminga 
Rev. Bras. Saúde Prod. Anim., Salvador, v.13, n.1, p.83-96 jan/mar, 2012 http://www.rbspa.ufba.br ISSN 15199940

(1995) afirmaram que a proporção de protozoários no rúmen diminuiu com o aumento nas taxas de ingestão de alimento, observaram redução no número de protozoários quando o CMS aumentou de 13,1 para $17,1 \mathrm{~kg} \mathrm{MS} / \mathrm{d}$ e atribuíram este resultado ao elevação na taxa de passagem. Taxa de passagem lenta aumenta o tempo de permanência dos protozoários no rúmen, o que favorece a manutenção desses nesse ambiente, uma vez que os protozoários apresentam elevado tempo de geração (acima de 24 horas).

Tabela 2. Variáveis, coeficientes, erro padrão dos coeficientes, razão $t$ e valores de $p$ para o modelo de regressão estimado para protozoários totais versus raça e CMS (Kg)

\begin{tabular}{|c|c|c|c|c|}
\hline Variáveis & Coeficientes & Erro Padrão & Razão $t$ & Valor de $p$ \\
\hline Constante & 20111 & 3296 & 6,10 & 0,000 \\
\hline raça $_{1}$ & -6205 & 1280 & $-4,85$ & 0,000 \\
\hline raiz $\mathrm{CMS}$ & $-3184,3$ & 961,9 & $-3,31$ & 0,005 \\
\hline & $s=2519,93$ & $\mathrm{n}=18 \quad \mathrm{R}^{2}=66,5 \%$ & $p=0,000$ & \\
\hline
\end{tabular}

O efeito da variação da taxa de diluição ou da taxa de passagem em meios de cultivo de micro-organismos tem sido demonstrado por alguns autores e também percebido que para uma determinada população de microorganismos, a reduzida taxa de diluição do fermentador causa aumento da reciclagem de conteúdos celulares, incluindo $\mathrm{N}$ e redução da eficiência microbiana (g massa microbiana/kg de carboidrato utilizado), conforme Madigan \& Martinko, 2006.

Para o número de protozoários totais ruminais ( $\mathrm{x} \quad 10^{4}$ células $/ \mathrm{mL}$ ) contra as variáveis independentes, aditivo, peso e FDN, foi obtida a seguinte equação de regressão ajustada:

$$
\operatorname{Raiz}(\hat{Y})=25,007-2,9867 \text { aditivo }+0,0039 \text { peso }(\mathrm{Kg})+0,4573 \text { FDN }(\%)-6,048 \text { raiz }(\mathrm{FDN})
$$

O peso exerceu efeito significativo sobre a microbiota ruminal. Animais de maior peso apresentam maior volume de pré-estômagos, portanto abrigam maior número de micro-organismos (Tabela 3). Outro fator que pode explicar este resultado é que quanto maior o peso do animal, maior $o$ consumo alimentar, com mais nutrientes aportados no rúmen, maior a quantidade de energia disponível para crescimento da microbiota. Oliveira et al. (2007) afirmam que o alimento ingerido pelo animal proporciona um aporte constante de substratos que é retido por tempo e volume necessários para que os componentes da dieta sejam degradados e fermentados pelos micro-organismos ruminais.

A variável independente FDN foi utilizada no modelo com dois efeitos distintos para se obter um melhor ajuste. Para Dijkstra e Tamminga (1995) o aumento dos níveis de FDN na dieta não afetam o número de protozoários totais. Entretanto, o aumento do teor de FDN possibilita a manutenção do $\mathrm{pH}$ ruminal numa faixa adequada para 
Rev. Bras. Saúde Prod. Anim., Salvador, v.13, n.1, p.83-96 jan/mar, 2012 http://www.rbspa.ufba.br ISSN 15199940

os protozoários ruminais, e segundo Matos et al. (2008), dietas ricas em fibras proporcionam maior tempo de ruminação e, consequentemente, maior produção de saliva, o que eleva o $\mathrm{pH}$ ruminal.

Benez (2007) faz uma associação entre os teores de FDN da dieta e o CMS ao afirmar que quanto maior os níveis de FDN, menor a ingestão da matéria seca, e associa este fator à menor taxa de passagem da FDN em relação a outros nutrientes da dieta, que tem como consequência maior tempo de permanência da digesta nos préestômagos. Isto explica o aumento do número de protozoários em função do aumento dos níveis de FDN na dieta.

Tabela 3. Variáveis, coeficientes, erro padrão dos coeficientes, razão $t$ e valores de $p$ para o modelo de regressão estimado para protozoários totais versus aditivo, peso $(\mathrm{Kg})$ e FDN $(\%)$

\begin{tabular}{lcccc}
\hline Variáveis & Coeficientes & Erro Padrão & Razão $t$ & Valor de $p$ \\
\hline Constante & 25,007 & 7,584 & 3,30 & 0,003 \\
Aditivo & $-2,9867$ & 0,3960 & $-7,54$ & 0,000 \\
Peso (Kg) & 0,0039 & 0,0015 & 2,60 & 0,016 \\
FDN (\%) & 0,4573 & 0,1622 & 2,82 & 0,009 \\
Raiz FDN & $-6,048$ & 2,296 & $-2,63$ & 0,015 \\
\hline & $s=1,00325$ & $\mathrm{n}=29$ & $\mathrm{R}^{2}=80,8 \%$ & $p=0,000$ \\
\end{tabular}

Para Lopes et al. (2002) a presença de protozoários no rúmen permite a manutenção de ambiente estável e adequado à digestão in situ dos componentes da parede celular, uma vez que aumenta a taxa de passagem e auxilia na redução do efeito da FDN sobre a repleção ruminal.

Franzolin et al. (2002) observaram que as concentrações totais de protozoários do conteúdo ruminal elevaram-se até o nível de $66 \%$ de FDN na ração, com queda acentuada à medida que este valor foi ultrapassado.

$\mathrm{Na}$ Figura 2 são apresentadas as estimativas da concentração de protozoários totais no rúmen em função do teor de FDN na dieta, na ausência de aditivos, com base na equação (3). Pode ser visualizado que o aumento do teor de FDN na dieta promove incremento na concentração de protozoários, cujo mecanismo envolve aspectos: nutricionais, pois, a maioria dos protozoários (Entodinium) do rúmen utiliza os componentes fibrosos dos alimentos como fonte de energia para crescimento; físico-químicos, pois o aumento do teor de FDN promove a manutenção do $\mathrm{pH}$ ruminal acima de 6,2 , valor este considerado favorável à maioria dos protozoários ruminais; e do efeito da fibra em reduzir a taxa de passagem de partículas no rúmen, e com isso ocorre aumento do tempo de permanência dos protozoários neste compartimento.

Para o número de protozoários totais ruminais ( $\mathrm{x} 10^{4}$ células $\left./ \mathrm{mL}\right)$ contra as variáveis independentes $\mathrm{PB}$ e aditivo foi obtida a seguinte equação de regressão ajustada:

$$
\operatorname{Raiz}(\hat{Y})=12,6401-0,3943 \text { PB }(\%)-2,7333 \text { Aditivo }
$$


Rev. Bras. Saúde Prod. Anim., Salvador, v.13, n.1, p.83-96 jan/mar, 2012 http://www.rbspa.ufba.br ISSN 15199940

$\mathrm{Na}$ Tabela 4 são apresentados os coeficientes dos parâmetros da regressão, o erro padrão dos coeficientes, a razão da estatística $t$, os $p$ valores para cada coeficiente, o desvio padrão do modelo, o valor de $n$, o coeficiente de determinação $\left(\mathrm{R}^{2}\right)$ e o valor de $p$ do modelo.

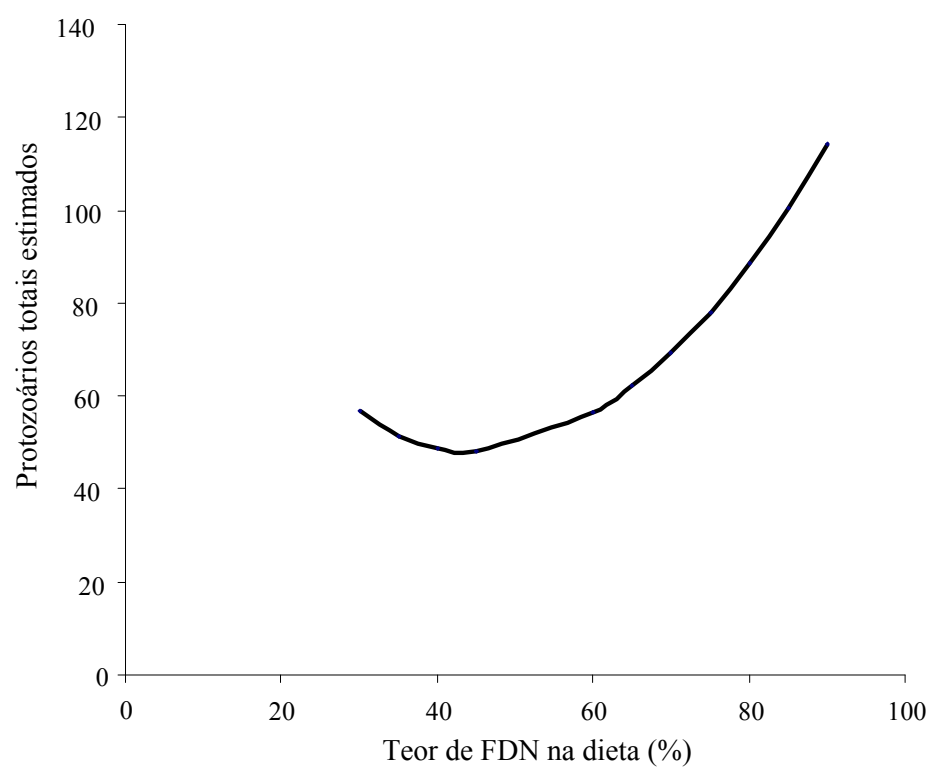

Figura 2. Estimativa do número de protozoários totais no rúmen (x $10^{4}$ células $/ \mathrm{mL}$ ) em função do teor de FDN na dieta (sem aditivos)

Tabela 4. Variáveis, coeficientes, erro padrão dos coeficientes, razão $t$ e valores de $p$ para o modelo de regressão estimado para protozoários totais versus $\mathrm{PB}(\%) \mathrm{e}$ aditivo

\begin{tabular}{|c|c|c|c|c|}
\hline Variáveis & Coeficientes & Erro Padrão & Razão $t$ & Valor de $p$ \\
\hline Constante & 12,6401 & 0,8141 & 15,53 & 0,000 \\
\hline PB $(\%)$ & $-0,3943$ & 0,0635 & $-6,21$ & 0,000 \\
\hline \multirow[t]{2}{*}{ Aditivo } & $-2,7333$ & 0,4750 & $-5,75$ & 0,000 \\
\hline & $s=1,27605$ & $\mathrm{n}=35 \quad \mathrm{R}^{2}=73,9 \%$ & $p=0,000$ & \\
\hline
\end{tabular}

Na Figura 3 são apresentadas estimativas da concentração de protozoários totais em função do teor de PB na dieta, por meio da equação (4). Pode ser observado que o aumento do teor de $\mathrm{PB}$ da dieta promove redução do número de protozoários totais, comportamento este também observado por Dijkstra (1994) em seu trabalho de simulação da dinâmica de protozoários do rúmen. Embora fosse esperado que o aumento do teor de proteína na dieta promovesse aumento do crescimento de micro-organismos do rúmen, inclusive de protozoários, o efeito benéfico da inclusão de proteína seria marcante quando a dieta basal apresenta quantidade limitada de proteína à microbiota ruminal. Para Cavalcante et al. (2006), a adição de 
níveis crescentes de proteína bruta às dietas, não altera $\mathrm{o} \mathrm{pH}$, a eficiência microbiana e a taxa de passagem da digesta. No entanto, Coalho et al. (2003), afirmaram que o nível de proteína bruta na ração não favorece a elevação da densidade populacional de ciliados. Ao se considerar que os carboidratos são fonte principal de energia para a microbiota ruminal (protozoários), o aumento do teor de PB causa redução na quantidade de carboidratos, o que pode afetar o crescimento dos protozoários por limitação da disponibilidade de energia. Pois, para que ocorram os eventos celulares relacionados ao processo de crescimento microbiano que envolvam replicação do DNA, transcrição do DNA (síntese de RNAm, RNAt e RNAr) e traduação (síntese proteica), a energia é fator limitante.

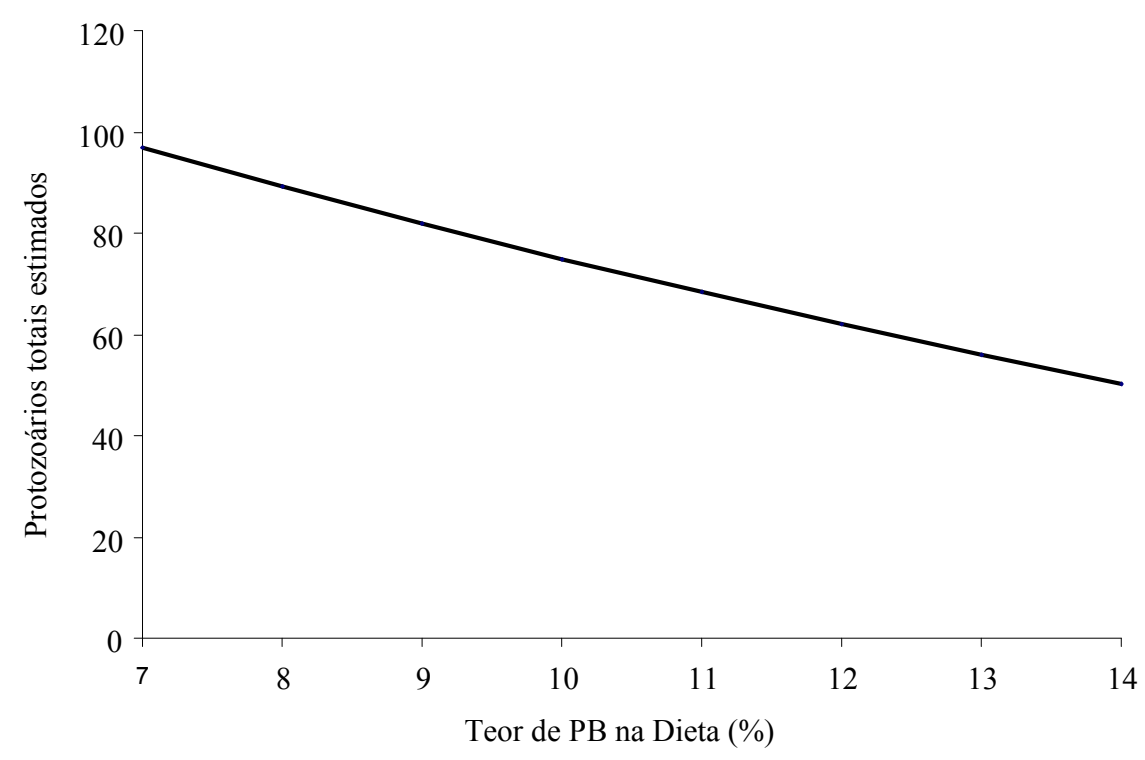

Figura 3. Estimativa do número de protozoários totais no rúmen (x $10^{4}$ células $/ \mathrm{mL}$ ) em função do teor de $\mathrm{PB}$ na dieta (sem aditivos)

Outro mecanismo relacionado ao aumento do teor de PB e o seu efeito sobre a redução da população de protozoários totais refere-se ao possível efeito positivo da PB sobre o consumo de matéria seca pelo animal, condição esta que pode aumentar a taxa de passagem de partículas para fora do rúmen, o que reduz o tempo de permanência dos protozoários para realizarem a duplicação celular.

Em ruminantes, a quantidade $\mathrm{e}$ qualidade de nutrientes absorvidos no trato digestivo geralmente difere dos nutrientes ingeridos devido à atividade microbiana (DIJKSTRA, 1994). A significância dos microorganismos ruminais, particularmente dos ciliados, nos processos digestivos e consequentemente na produção animal tem sido vastamente explorada, mas ainda assim o conhecimento sobre protozoários ruminais e suas funções é incipiente, quando comparado ao conhecimento sobre a população bacteriana. Jouany et al. (1988) fizeram inferência a este respeito ao afirmarem que desde que o metabolismo bacteriano e dos protozoários difere em muitos aspectos, estabelecer o papel dos protozoários no 
processo digestivo e determinar os efeitos da defaunação neste processo deveria incluir a complexa relação entre protozoários, bactérias, animal e dieta. Portanto, uma abordagem que possibilita incrementar o entendimento sobre a interação entre os vários componentes de um sistema biológico é a representação matemática que envolva a formulação de equações (THRORNLEY \& JOHNSON, 1990). No domínio agrícola, em especial na área animal, o número de metaanálises publicadas tem aumentado nos últimos anos (LOVATTO \& SAUVANT, 2002; MARTIN \& SAUVANT, 2002; OFFNER et al., 2003; EUGÈNE et al., 2004), o que sinaliza que esse procedimento pode se tornar rotina nesse campo da ciência.

A simulação dos efeitos dos componentes dietéticos sobre a microbiota ruminal, especificamente sobre os protozoários, possibilita obter informações quantitativas importantes, as quais permitem promover um melhor entendimento do ecossistema ruminal e meios de manipulá-lo de forma a atingir determinados objetivos.

Ao se considerar a necessidade premente de aumentar o desempenho produtivo dos animais para atender a crescente demanda da população mundial por proteína animal, aliada ao aumento da eficiência de uso dos nutrientes pelo animal, de tal forma que permita reduzir a excreção de nutrientes (metano, nitrogênio, fósforo, etc.) e o impacto ambiental da emissão desses, o desenvolvimento de equações que permitam uma melhor compreensão do ecossistema ruminal é crucial para os sistemas de produção de ruminantes nos dias atuais.

Com base nos resultados e discussões aqui apresentados conclui-se que, à medida que o $\mathrm{pH}$ aumenta, ocorre um aumento no número de protozoários totais; o aumento no CMS e a presença de aditivos, diminuem a população de protozoários ruminais; o aumento do teor de FDN na dieta promove incremento no número de protozoários; quanto maior o teor de $\mathrm{PB}$, menor o número de protozoários totais; a raça $\mathrm{e}$ o peso do animal exercem influência sobre a população de protozoários; os modelos estatísticos obtidos permitem estimar o número de protozoários em função das variáveis $\mathrm{pH}, \mathrm{CMS}, \mathrm{FDN}$, $\mathrm{PB}$ e aditivos.

\section{REFERÊNCIAS}

ARAÚJO, J.S.; PÉREZ, J.R.O.; OLIVEIRA, V.; BRAGA, G.C.; PEIXOTO, E.C.T.M.; SALVADOR, F.M.; TSUZUKI, N. Monensina sódica no consumo e digestibildade aparente das fibras em detergente neutro e ácido da dieta em ovinos. Archives of

Veterinary Science, v.12, n.1, p. 28-34, 2007.

BENEZ, A.L.C. Parâmetros ruminais

e consumo voluntário de feno de Brachiaria decumbens por bovino recebendo suplementação protéicoenergética. 2007.53p. Dissertação (Mestrado em Ciências Agrárias) Faculdade de Agronomia e Medicina Veterinária, Universidade de Brasília, Brasília.

BURGER, P.J., PEREIRA, J.C.; VALADARES FILHO S.C.; SILVA, J.F.C.; QUEIROZ, A.C.; CECON, P.R.; MAGIERO, D. Fermentação ruminal e eficiência microbiana em Bezerros Holandeses Alimentados com dietas contendo diferentes níveis de concentrado. Revista Brasileira de Zootecnia, v.29, n.1, p.215-224, 2000. 
Rev. Bras. Saúde Prod. Anim., Salvador, v.13, n.1, p.83-96 jan/mar, 2012 http://www.rbspa.ufba.br ISSN 15199940

CAVALCANTE, M.A.B.; PEREIRA, O.G.; VALADARES FILHO, S.C.; RIBEIRO, K.G.; PACHECO, L.B.B.; ARAÚJO, D.; LEMOS, V.M.C. Níveis de proteína bruta em dietas para bovinos de corte: parâmetros ruminais, balanço de compostos nitrogenados e produção de proteína microbiana. Revista

Brasileira de Zootecnia, v.35, n.1, p.203-210, 2006.

CECAVA, M.J.; MERCHEN, N.R.; BERGER, L.L.; MACKIE, R.I.; FAHEY JÚNIOR, G.C. Effects of dietary energy level and protein source on nutrient digestion and ruminal nitrogen metabolism in steers. Journal of Animal Science, v.69, p.2230-2243, 1991.

COALHO, M.R.; NOGUEIRA-FILHO, J.C.M.; CUNHA, J.A.; LIMA, C.G. Estudo dos protozoários ciliados em bovinos consumindo dietas com diferentes níveis de proteína não degradável no rúmen. Acta Scientiarum, v.25, n.1, p.193-199, 2003.

DIAS, H.L.C.; VALADARES FILHO, S.C.; COELHO SILVA, J.F.; PAULINO, M.F.; CECON, P.R.; VALADARES, R.F.D.; RENNÓ, L.N.; COSTA, M.A.L. Eficiência de síntese microbiana, $\mathrm{pH}$ e concentrações ruminais de amônia em novilhos $\mathrm{F}_{1}$ Limousin $\mathrm{x}$ Nelore alimentados com dietas contendo cinco níveis de concentrado. Revista Brasileira de Zootecnia, v.29, n.2, p.555-563, 2000.

DIJKSTRA, J. Simulation of the dynamics of protozoa in the rumen. British Journal of Nutrition, v.72, p.679-699, 1994.

DIJKSTRA, J.; TAMMINGA, S. Simulation of the effects of diet on the contribution of rumen protozoa to degradation of fibre in the rumen. British Journal of Nutrition, v.74, p.617-634, 1995.
DOMINGUES, J.L. Avaliação do desempenho em confinamento do metabolismo ruminal e do perfil de ácidos graxos da carne em bovinos nelore, utilizando milho com alto teor de óleo nas dietas de terminação. 2006. 101p. Tese (Doutorado) - Faculdade de Zootecnia e Engenharia de Alimentos, Universidade de São Paulo, Pirassununga.

EUGÈNE, M.; ARCHIMÈDE, H.; SAUVANT, D. Quantitative metaanalysis on the effects of defaunation of the rumen on growth, intake and digestion in ruminants.Livestock Production Science, v.85, p.81-97, 2004.

FORTALEZA, A.P.S.; SILVA, L.D.F.; RIBEIRO, E.L.A.; BARBERO, R.P.; MASSARO JR., M.L.; SANTOS, A.X.; CASTRO, V.S.; CASTRO, F.A.B. Degradabilidade ruminal In Situ dos componentes nutritivos de alguns suplementos concentrados usados na alimentação de bovinos. Semina: Ciências Agrárias, v.30, n.2, p.481-496, 2009.

FRANZOLIN, D.; DEHORITY, B.A. The role of $\mathrm{pH}$ on the survival of rumen protozoa in steers. Revista Brasileira de Zootecnia, v.39, n.10, p.2262-2267, 2010.

FRANZOLIN, R.; FRANZOLIN, M.H.T. População de protozoários ciliados e degradabilidade ruminal em búfalos e bovinos zebuínos sob dieta à base de cana-de-açúcar. Revista Brasileira de Zootecnia, v.29, n.6, p.1853-1861, 2000.

FRANZOLIN, M.H.T.; SILVEIRA, A.C.; FRANZOLIN, R. Efeitos de dietas com diferentes níveis de fibra em detergente neutro e do tamanho de poros de sacos de náilon incubados no rúmen sobre a fauna ruminal em bubalinos e bovinos. Revista Brasileira de Zootecnia, v.31, n.2, p.716-723, 2002. 
Rev. Bras. Saúde Prod. Anim., Salvador, v.13, n.1, p.83-96 jan/mar, 2012 http://www.rbspa.ufba.br ISSN 15199940

GOMES, R.C.; ANTUNES, M.T.; NOGUEIRA FILHO, J.C.M.; ÍTAVO, L.C.V.; LEME, P.R. Leveduras vivas monensina em dietas de alto concentrado para bovinos: parâmetros ruminais e degradabilidade "in situ".

Revista Brasileira de Saúde e Produção Animal [Online], v.11, n.1, p.202-216, 2010.

GONÇALVES, A.L.; LANA, R.P.; RODRIGUES, M.T.; VIEIRA, R.A.M.; QUEIROZ, A.C.; HENRIQUE, D.S. Padrão Nictemeral do $\mathrm{pH}$ Ruminal e Comportamento Alimentar de cabras leiteiras alimentadas com dietas contendo diferentes relações volumoso:concentrado. Revista Brasileira de Zootecnia, v.30, n.6, p.1886-1892, 2001.

HOOVER, W.H.; STOKES, S.R. Balancing carbohydrates and proteins for optimum rumen microbial yield. Journal of Dairy Science, v.74, n.10, p.3630-3644, 1991.

JOUANY, J.P.; DEMEYER, D.I.; GRAIN, J. Effect of defaunating the rumen. Animal Feed Science and Technolology, v.21, n.2-4, p.229-265, 1988.

KITTELMANN, S.; JANSSEN, P.H. Caracterização da composição da comunidade de ciliados ruminais em ovinos domésticos, veados e gado, alimentando-se de dietas variadas, por meio de PCR-DGGE e bibliotecas clone. Microbiology Ecology, v.75, n.3, p.407428, 2002.

LOPES, F.C.F.; AROEIRA, L.J.M.; ARCURI, P.B.; DAYRELL, M.S.; VITTORI, A. Efeitos da defaunação em ovinos alimentados com cana-de-açúcar (Saccharum officinarum, L.) adicionada de uréia. Arquivo Brasileiro de Medicina Veterinária e Zootecnia, v.54, n.2, p.180$188,2002$.
LOVATTO, P.A.; SAUVANT, D. Métaanalyse et modélisation de l'ingestion volontaire chez le porc en croissance.Journées Rech. Porcine en France, v.34, p.129-134, 2002.

MACKIE, R.I.; McSWEENEY,C.S.; KLIEVE, A.V. Microbial ecology of the ovine rumen. In: FREER, M.; DOVE, H. (Eds). Sheep Nutrition. Wallingford: CAB International, 2002, 377p.

MADIGAN, M.T.; MARTINKO, J.M. Brock biology of microorganisms. 11.ed. New Jersey: Pearson, 2006, 992p.

MANELLA, M.Q.; LOURENÇO, A.J. População de protozoários ciliados no rúmen de bovinos nelore em pastos de Brachiaria brizantha marandu recebendo suplemento protéico ou com livre acesso a banco de proteína de Leucena leucocephala nas diferentes estações do ano. Boletim de Indústria Animal, n.1, p.1-11, 2004.

MARTIN, O.; SAUVANT, D. Metaanalysis of input/output kinetics in lactating dairy cows.Journal Dairy Science, v.85, p.3363-3381, 2002.

MARTINELE, I.; SIQUEIRA-CASTRO, I.C.V.; D'AGOSTO, M. Protozoários ciliados no rúmen de bovinos alimentados com dietas de capim-elefante e com dois níveis de concentrado. Revista Brasileira de Saúde e Produção Animal [Online], v.9, n.1, p.74-81, 2008a.

MARTINELE, I.; EIFERT, E.C.; LANA, R.P.; ARCURI, P.B.; D'AGOSTO, M. Efeito da monensina e do óleo de soja sobre os protozoários ciliados do rúmen e correlação dos protozoários com parâmetros da fermentação ruminal e digestivos. Revista Brasileira de Zootecnia, v.37, n.6, p.1129-1136, 2008 b. 
Rev. Bras. Saúde Prod. Anim., Salvador, v.13, n.1, p.83-96 jan/mar, 2012 http://www.rbspa.ufba.br ISSN 15199940

MATOS, D.S.; GUIM, A.; BATISTA, A.M.V.; SANTOS, M.V.F.; CORREA, I.M.; SANTOS, G.R.A.; LOPES, C.R.A. População de protozoários ciliados no rúmen de ovinos criados na caatinga de Pernambuco. Revista Brasileira de Saúde e Produção Animal [Online], v.9, n.2, p.270-279, 2008.

MINITAB 15, Software Estatístico, versão 15.1.3., tamanho $96 \mathrm{MB}$, sistema XP, Empresa lidersoftwares, 2010.

NAGARAJA, T.G.; TOWNE, G.; BEHARKA, A.A. Moderation of ruminal fermentation by ciliated protozoa in cattle fed a High-Grain diet. Applied Environmental Microbiology, v.58, n.8, p.2410-2414, 1992.

NOGUEIRA FILHO, J.C.M.; OLIVEIRA, M.E.M.; TOLEDO, L.R.A.; VELLOSO, L. Protozoários ciliados no rúmen de zebuínos e bubalinos submetidos a dietas com volumosos e concentrados. Revista Pesquisa Agropecuária Brasileira, v.33, n.6, p.993-999, 1998.

NOGUEIRA FILHO, J.C.M.; OLIVEIRA, M.E.M.; ABLAS, D.S.; TITTO, E.A.L.; TOLEDO, L.R.A.; OLIVEIRA, T.S.B.M. Fauna ciliada do rúmen de zebuínos e bubalinos em Pirassununga, São Paulo, Sudeste do Brasil. Acta Scientiarum, v.22, n.3, p.663-668, 2000.

NOGUEIRA FILHO, J.C.M.; OLIVEIRA, M.E.M.; CUNHA, J.A.,TOLEDO, L.R.A. Volume líquido e taxa de turnover no rúmen de zebuínos e bubalinos submetidos a dietas com volumosos e concentrados e sua relação com protozoários ciliados. Ciência Animal Brasileira, v.5, n.1, p.1-7, 2004.
OFFNER, A.; BACH, A.; SAUVANT, D. Quantitative review of in situ starch degradation in the rumen. Animal Feed Science and Technology, v.106, n.1-4, p.81-93, 2003.

OLIVEIRA, J.S.; ZANINE, A.M.; SANTOS, E.M. Diversidade microbiana no ecossistema ruminal (Microbial diversity in the ecossistema ruminal). Revista electrónica de Veterinaria, v.3, n.6, p. 1695-7504, 2007.

ORTOLAN, J.H. Efeitos da levedura, monensina sódica e salinomicina na degradabilidade, digestibilidade, parâmetros ruminais e protozoários ciliados de novilhos Nelore arraçoados com dietas concentradas. 2005. 61p. Dissertação (Mestrado) Faculdade de Zootecnia e Engenharia de Alimentos, Universidade de São Paulo, Pirassununga.

RISPOLI, T.B.; RODRIGUES, I.L.; MARTINS NETO, R.G.; KAZAMA, R.; PRADO, O.P.P.P.; ZEOULA, L.M.; ARCURI, P.B. Protozoários ciliados do rúmen de bovinos e bubalinos alimentados com dietas suplementadas com monensina ou própolis. Pesquisa Agropecuária Brasileira, v.44, n.1, p.92-97, 2009.

RIVERA, A.R. Estudo da fermentação ruminal por bovinos consumindo feno de tifton 85 e concentrado com aditivos. 2006. 57p. Dissertação (Mestrado em Zootecnia) Faculdade de Ciências Agrárias e Veterinárias, Universidade Estadual de São Paulo, Jaboticabal.

RUSSEL, J.B.; RYCHLIK, J.L. Factors that alter rumen microbial ecology. Science, v.292, p.1119-1122, 2001. 
Rev. Bras. Saúde Prod. Anim., Salvador, v.13, n.1, p.83-96 jan/mar, 2012 http://www.rbspa.ufba.br ISSN 15199940

SÁLVIO, G.M.M.; D'AGOSTO, M.

Ciliados nas cavidades do estômago dos bovinos. Arquivo Brasileiro de Medicina Veterinária e Zootecnia, v.53, n.6, p.686-690, 2001.

SARAN NETTO, A.; ZANETTI, M.A.; PAIVA, F.A.; SALLES, M.S.V.; DEL CLARO, G.R.; LOPES, L.C.; NOGUEIRA FILHO, J.C.M. Efeitos da fonte de enxofre sobre a população de protozoários e degradabilidade no rúmen. Arquivo Brasileiro de Medicina Veterinária e Zootecnia, v.61, n.4, p.910-917, 2009.

SOARES, P.C.; MARTINELE, M.D.; MARUTA, C.A.; SUCUPIRA, M.C.A.; ANTONELLI, A.C.; MORI, C.S.; ORTOLANI, E.L. Effect of an energydeficient diet on populations of ciliate protozoans in bovine rumen. Arquivo Brasileiro de Medicina Veterinária e Zootecnia, v.60, n.1, p.148-155, 2008.

THORNLEY, J.H.M.; JOHNSON, I.R. Plant and crop modeling. A mathematical approach to plant and crop physiology. Oxford: Clarendon Press, 1990.
VALINOTE, A.C.; NOGUEIRA FILHO, J.C.M.; LEME, P.R.; SILVA, S.L.; CUNHA, J.A. Fontes de Lipídeos e monensina na alimentação de novilhos Nelore e sua relação com a população de protozoários ciliados do rúmen.

Revista Brasileira de Zootecnia, v.34, n.4, p.1418-1423, 2005.

VAN SOEST, P.J. Nutritional ecology of the ruminant. 2.ed. New York: Cornell University Press, 1994. 476p.

VIDAL, J.M.; PAIVA, P.C.A.; ARCURI, P.B., LOPES, F.C.F.; ZAQUINI, L. Efeito de diferentes doses de enxofre no consumo voluntário e nas populações de protozoários do rúmen de novilhas mestiças alimentadas com capim-elefante de baixa qualidade. Ciência e Agrotecnologia, v.31, n.1, p.218-222, 2007.

Data de recebimento: 03/08/2011

Data de aprovação: 09/02/2012 